\title{
Influence of the surface properties of the connector material on the reliable and reproducible contacting of battery cells with a laser beam welding process
}

\author{
Johanna Helm ${ }^{1}$ (D) $\cdot$ Ingo Dietz von Bayer ${ }^{2} \cdot$ Alexander Olowinsky $^{1} \cdot$ Arnold Gillner $^{1}$
}

Received: 29 September 2018 / Accepted: 3 March 2019 / Published online: 22 June 2019

(C) The Author(s) 2019

\begin{abstract}
The increasing electrification of the automotive industry leads to a growing demand for high-performance energy storage systems. Three different cell types are used for the construction and production of battery modules or packs. These include, for example 18650 round cells, prismatic cells or pouch cells. For the electrical interconnection of prismatic energy storage devices or round cells, the laser bonding method can be used as a particularly flexible connection technology. This method combines the technique of a conventional wire bonder with laser beam welding. Compared to wire bonding, wider and thicker connectors can be contacted, and thus higher currents can be transmitted. During the production of wires/ribbons for wire bonding, sometimes complicated and costly process steps are necessary in order to ensure a consistently high quality of the produced material and consequently obtain a reproducible wire bonding process. Unfortunately, a polished and hence highly reflective surface of an aluminium or copper ribbon adversely affects the reliability of the laser beam welding process. A rough or oxidised ribbon surface however can favour the coupling of the laser radiation into the copper material and thus contribute to a stable process sequence. In this work, the influence of the surface properties of pure copper ribbons regarding the process reliability is investigated. Therefore, ribbons produced for a wire bonding process are thermally oxidised or mechanically roughened, and their optical properties are compared with a polished reference material. The sample ribbons are welded with a continuous wave fibre laser, and the mechanical properties of the resulting connection are investigated. Due to a more stable interaction of the laser radiation, a mechanically and electrically improved connection is expected.
\end{abstract}

Keywords Laser microwelding $\cdot$ Copper $\cdot$ Fibre laser $\cdot 18650$ battery cells $\cdot$ Ribbon $\cdot$ Oxidised surface

\section{Introduction}

Under the second commitment period of the Kyoto Protocol, the European Union has committed itself to reducing its greenhouse gas emissions by $20 \%$ compared to 1990 . The reduction of $\mathrm{CO}_{2}$ plays an important role in reaching this aim. Figure 1 shows Germany's $\mathrm{CO}_{2}$ emissions in 2015 by

Recommended for publication by Commission IV - Power Beam Processes

Johanna Helm

johanna.helm@ilt.fraunhofer.de

1 Fraunhofer Institute for Laser Technology ILT, Steinbachstr. 15, 52074 Aachen, Germany

2 FH Aachen University of Applied Sciences, Aachen, Germany sector. The transport sector is the third largest source of influence on Germany's $\mathrm{CO}_{2}$ emissions.

For this reason, emission-free, purely electric vehicles socalled battery electric vehicles (BEV) are becoming increasingly important for achieving set climate targets. The core of a BEV is the battery pack, which in turn consists of several battery modules containing interconnected battery cells. Due to their high energy density, Li-ion battery cells are mainly used.

High demands on battery technology in terms of energy density and service life entail the need to further intensify research in cell chemistry on the one hand and to optimise joining technologies on the other. Requirements for the connection technology include low additional weight, high reliability and suitability for mass production. These requirements are fulfilled, for example by wire bonding. However, conventional wire bonding is limited in terms of the possible 


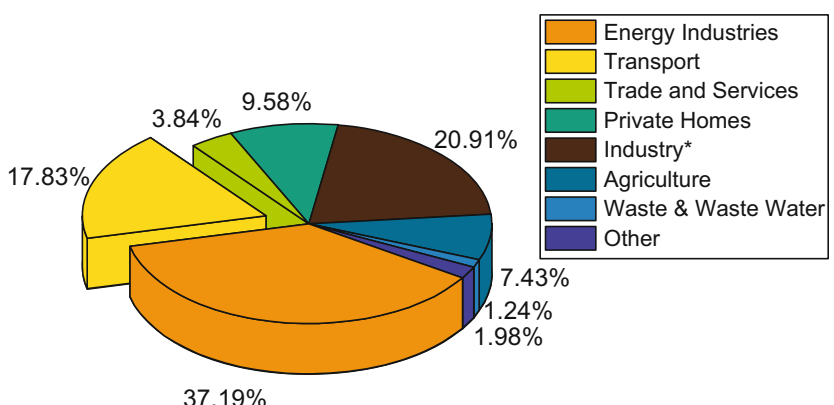

Fig. 1 Emissions of greenhouse gases in accordance with the UN climate convention (Germany, 2015) [1] (*energy- and process-related emissions from industry)

connection cross-sections, which in turn limits the maximum transferable current.

This limitation can be overcome by combining conventional wire bonding technology with laser microwelding. Furthermore, a material must be selected that provides high electrical conductivity and good processability regarding the bonding process. The use of copper ribbons ensures high electrical conductivity. However, laser welding of copper proves to be difficult due to material-specific properties.

Within this work, the surface properties of a copper ribbon are changed by controlled oxidation or roughening. The aim is to reduce the influence of the material-specific properties to improve the incoupling of the laser beam and therefore gain a larger connection area resulting in improved mechanical properties.

\section{State of the art}

\subsection{Laser beam welding}

Basically, two welding regimes are distinguished in the laser beam welding process: heat conduction welding and deep penetration welding. In heat conduction welding, the surface of the material is melted, whereby the energy is transported into deeper layers via heat conduction [2]. The maximum achievable aspect ratio (welding depth to seam width) is 1:1. During deep penetration welding, the intensity of the radiation exceeds the threshold intensity, and the material changes into a vaporous state. The vaporous material escapes from the base material, which leads to the formation of a counterforce in the depth direction of the material. This causes the formation of a vapour capillary (keyhole). Within this keyhole, the incident beam is reflected several times, which increases the degree of absorption. The resulting aspect ratio can exceed 10:1. These two welding regimes are shown in Fig. 2.
Heat Conduction

Deep Penetration

Welding (HCW)

Welding (DPW)

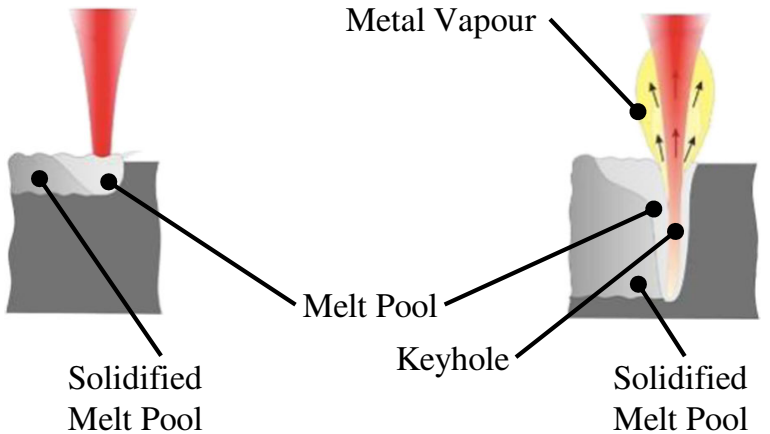

Fig. 2 Heat conduction welding (left) and deep penetration welding (right) $[3,4]$

\subsection{Spatial power modulation}

Spatial power modulation describes a linear feed rate with a superposed circular modulation. This technique enables a larger weld width compared to usual laser welding and thus a broader connection area. Furthermore, the melt dynamics can be controlled more easily, and the welding penetration depth is generally more constant [5]. The idea of spatial power modulation is shown in Fig. 3.

Spatial power modulation leads to an increase in weld seam width while simultaneously reducing the welding depth. This can be explained by the laser beam covering a larger area per unit of time. Due to heat conduction, the material melts in the middle of the circle figure resulting in an enlarged melt pool during the welding process. Consequently, wider connection cross-sections can be achieved [5].

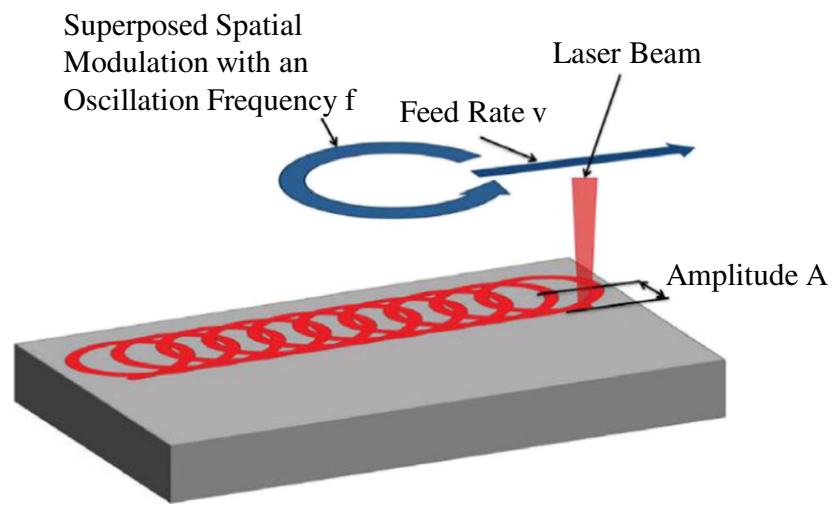

Fig. 3 Spatial power modulation: the beam path is the result of a linear feed rate $v$, the superposed oscillation frequency $f$ and the amplitude $A$ [6] 


\subsection{Welding of copper with highly brilliant laser beam sources}

Laser welding of copper has been regarded as a process that is difficult to master [4]. The difficulties are mainly due to the low absorption coefficient at room temperature for common beam sources such as $\mathrm{CO}_{2}$ or Nd:YAG lasers. Additionally, the absorption behaviour of copper changes during phase transition.

Highly brilliant fibre lasers have wavelengths in the NIR range, which means that the absorption coefficient for copper is approximately 4\% [7]. In contrast to short-wave beam sources, their brilliance is decisive for the successful welding of copper (Fig. 4).

The diffraction index $M^{2}$ of almost 1 facilitates high focusability for these laser beam sources. Thus, high intensities in the focus point are already achieved at low laser power, and therefore the amount of energy absorbed in copper needed to melt the material is reached.

\subsection{Wire bonding}

Wire bonding is a method of electrically contacting two or more contact points using a wire or ribbon. A distinction is made between thin wire and thick wire bonding. Thin wire bonding is a standard process in the semiconductor industry for example for making electrical connections between chip and board (chip on board).

In contrast to thin wire bonding, the larger material crosssection in thick wire bonding enables the transmission of higher electrical currents. This allows for example the connection of battery cells to battery modules with one wire only. Analogous to thin wire bonding, ultrasonic welding is usually used as a joining process. Ultrasonic welding limits the maximum connection width according to [8] to less than $3 \mathrm{~mm}$.

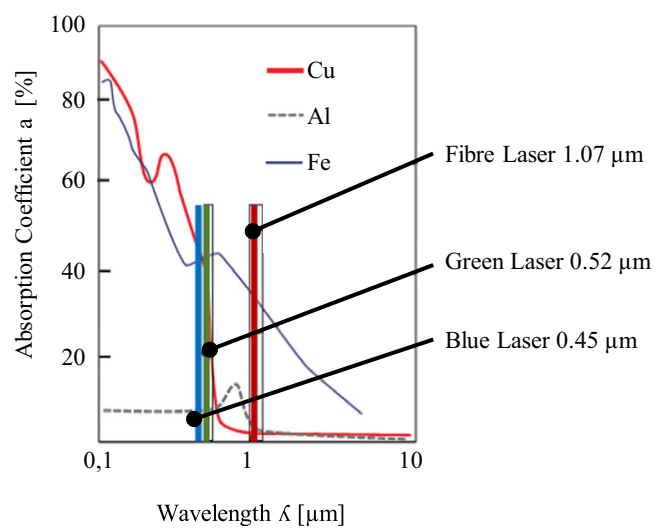

Fig. 4 Exemplary absorption coefficient of copper, aluminium and steel surfaces at room temperature over the wavelength [3]

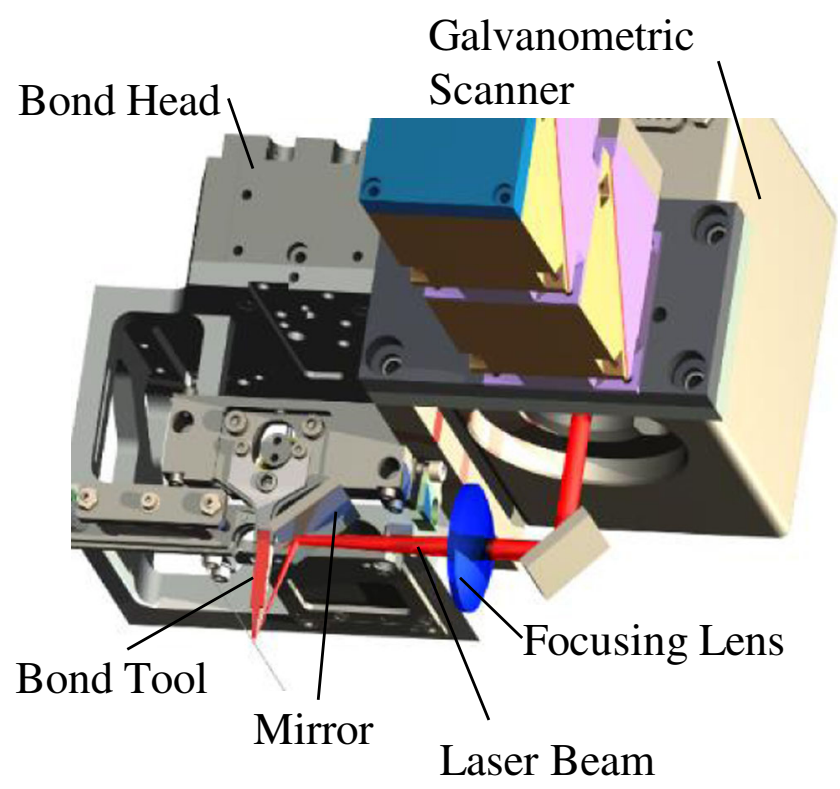

Fig. $53 \mathrm{D}$ view of the modified wire bonder head of the laserbonder [9]

\section{Experimental setup}

\subsection{Laserbonder}

The tests are carried out on the modified wire bonder described by [9] from F\&K Delvotec Bondtechnik GmbH, Ottobrunn, Germany. This prototype system was developed in cooperation with the Fraunhofer Institute for Laser Technology, Aachen, Germany, as part of the RoBE project (Robust Joints for Electric Vehicles) funded by the Federal Ministry of Education and Research (BMBF).

The interconnection method is no longer based on ultrasonic joining but is generated by a laser microwelding process. For this, the wire bonder was equipped with a single mode continuous wave fibre laser from SPI Lasers UK Ltd., Southampton, UK, with a maximum output power of $400 \mathrm{~W}$. The emitted laser radiation has a wavelength of $1070 \mathrm{~nm}$. The beam propagation factor $M^{2}$ is approximately 1.1 .

The fibre is connected to the modified wire bonder head as seen in Fig. 5. For the deflection of the beam in $x$ - and $y$ direction, a compact galvanometric scanner system SCANcube 25 by Scanlab GmbH, Puchheim, Germany, is used. The focusing lens has a focal length of $75 \mathrm{~mm}$, resulting in a focus diameter of $25 \mu \mathrm{m}$. In between the focusing lens and the bonder tool, a deflecting mirror is mounted, which is washed with nitrogen to prevent weld splatters and traces of powder from condensing on its surface.

\subsection{Preparation of the samples}

The tests are carried out with commercially available copper ribbon by Heraeus Deutschland GmbH \& Co. KG, Hanau, 

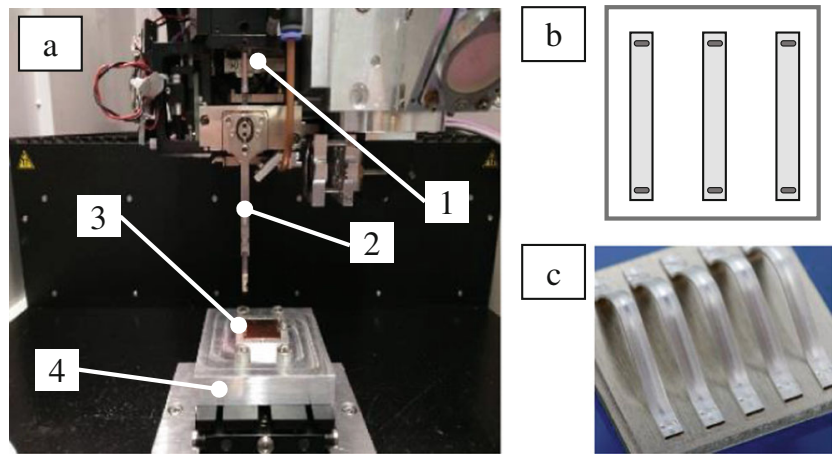

Fig. 6 Test setup a with bond head (1), bond tool (2), sample holder with substrate (3) and height-adjustable table (4). b shows a sketch of the resulting sample geometry and $\mathbf{c}$ shows a photo of a similar sample from former investigations (aluminium on aluminium); [10]

Germany. The ribbon has a width of $2000 \mu \mathrm{m}$ with a thickness of $300 \mu \mathrm{m}$. A square copper plate with an edge length of $24 \mathrm{~mm}$ and a thickness of $300 \mu \mathrm{m}$ is used as substrate for the test welds.

The substrate is clamped into a sample holder and placed underneath the modified bond head (Fig. 6). The copper ribbon is fed by the wire bonder and led to the sample plates, where it is held down onto the copper by the bond tool. As weld geometry, three straight lines with a length 1 of $1.8 \mathrm{~mm}$ and a line distance $x$ of $0.1 \mathrm{~mm}$ are chosen to exploit the width of the ribbon and therefore reach the maximum joint area without damaging neither the ribbon nor the bond tool. The laser power $P$ is set to $400 \mathrm{~W}$.

Amplitude $A$ and frequency $f$ of the superposed circular motion as well as the linear feed rate $v$ are set constant during all experiments. Consequently, the degree of overlap during spatial power modulation does not vary. The set laser and process parameters are shown in Table 1. Oxidised and roughened copper ribbons are produced for the experiments.

The mechanical properties of the welded ribbons are compared with those of untreated and welded specimens. The results allow conclusions to be drawn about the reliability and reproducibility of laser-welded copper connectors with modified surface properties.

Table 1 Parameters set constant during all experiments

\begin{tabular}{ll}
\hline Parameter & Value \\
\hline Laser power $P$ & $400 \mathrm{~W}$ \\
Linear feed rate $v$ & $80 \mathrm{~mm} / \mathrm{s}$ \\
Oscillation amplitude $A$ & $0.2 \mathrm{~mm}$ \\
Oscillation frequency $f$ & $1000 \mathrm{~Hz}$ \\
Number of lines $n$ & 3 \\
Length of weld lines $l$ & $1.8 \mathrm{~mm}$ \\
Distance between weld lines $x$ & $0.1 \mathrm{~mm}$ \\
\hline
\end{tabular}
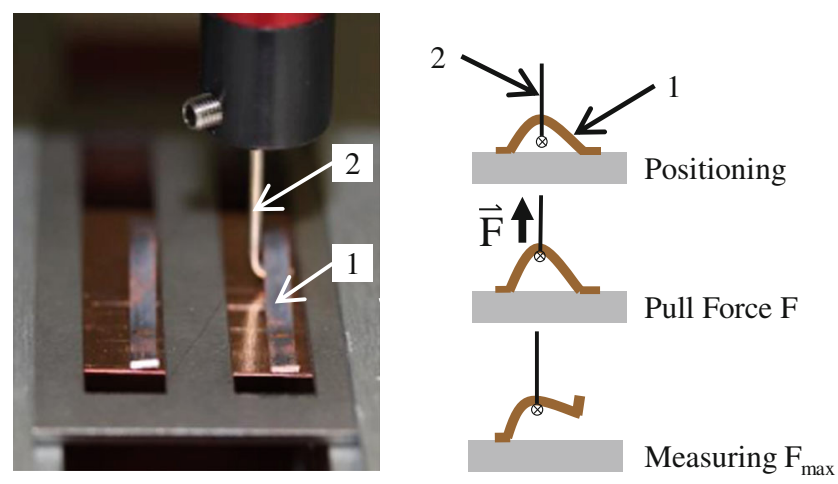

Fig. 7 Sequence of the pull testing of the samples. The hook (2) engages in the loop of the bond (1). The maximum force to separate the bond from the substrate is measured

\subsection{Determination of the tensile strength}

The tensile strength of the welds is determined by pull tests with the Bond Tester Condor Sigma from XYZTEC, Panningen, Netherlands. For this purpose, the bonds are positioned under the measuring device as shown in Fig. 7.

The hook engages in the loop of the bond. The force required to separate the bond from the substrate is measured in the $z$-direction. The connection area is quantified under the incident light microscope, and the tensile strength is determined from both values.

\section{Results and discussion}

\subsection{Oxidised samples}

The copper ribbon samples are heated in a laboratory oven at a pre-set temperature and time under ambient atmosphere to obtain a homogeneous oxide layer. The temperature control of the furnace allows the precise setting of a temperature profile over time. For the tests carried out in the course of this work, the temperature is always raised from room temperature to the target temperature with a ramp of $1.4 \mathrm{~K} / \mathrm{min}$. After the holding time has elapsed, the furnace is cooled conductively to room temperature. Two temperature steps and two holding times are selected for the preparation of the oxidised samples. Higher temperatures near the melting point of copper lead to a thick and very brittle oxide layer, resulting in chipping of said layer during handling. Therefore, processing on the laserbonder presented in Section 3.1 is not possible. An overview of the chosen parameters is shown in Table 2.

During oxidation at $300^{\circ} \mathrm{C}$ and a holding time of $5 \mathrm{~min}$, a firmly adhering, mostly black oxide layer is achieved. However, due to the low thickness of the oxide layer, the underlying copper still shines through (Fig. 8 a). At a holding time of $25 \mathrm{~min}$, the underlying copper is hardly visible, which indicates a much thicker oxide layer (Fig. 8 b). By increasing 
Table 2 Chosen temperature steps and holding times for the oxidised samples

\begin{tabular}{ll}
\hline Temperature & Holding time \\
\hline $300{ }^{\circ} \mathrm{C}$ & $5 \mathrm{~min}$ \\
$300{ }^{\circ} \mathrm{C}$ & $25 \mathrm{~min}$ \\
$450{ }^{\circ} \mathrm{C}$ & $5 \mathrm{~min}$ \\
$450{ }^{\circ} \mathrm{C}$ & $25 \mathrm{~min}$ \\
\hline
\end{tabular}

the temperature to $450{ }^{\circ} \mathrm{C}$ with the same holding times, a further increase in the oxide layer thickness is expected (Fig. $8 \mathrm{c}$ and d). After this oxidation process, a large number of detached fragments of the oxide layer are found on the bottom of the ceramic shell. Possible reasons for this detachment are thermal residual stresses within the oxide layer or a low adhesion to the non-oxidised sample material.

It must also be taken into account that the mechanical and electrical properties may change as a result of the heat treatment.

The reflectance of the treated samples is measured and compared with the reflectance of untreated copper ribbon. Figure 9 shows the relative reflectance of the oxidised samples compared to untreated copper ribbons. The reflection factor of the bare copper is set as $100 \%$ and indicated by a horizontal line. It is assumed that the transmittance of solid copper is zero. Thus, the absorption of the oxidised samples can be estimated from the graph.

In the range from 1000 to $1500 \mathrm{~nm}$, all curves show a similar course. Especially in the area of the used fibre lasers $(1070 \mathrm{~nm})$, the reflectance of the oxidised samples (range 38$62 \%$ of the reference reflectance) is significantly lower than for untreated copper, whereby an earlier melting of the ribbon and a more stable process sequence are expected. Between the two samples, which were oxidised at $300^{\circ} \mathrm{C}$, an improvement in the degree of reflectance of about 20 percentage points can be observed. Oxidation at higher temperatures $\left(450{ }^{\circ} \mathrm{C}\right)$ and the same holding times results in only a slightly lower reflectance for the wavelength under consideration. In the range between 700 and $850 \mathrm{~nm}$, the reflection measurement shows irregularities in the curve of the samples, which were oxidised at $450{ }^{\circ} \mathrm{C}$. These irregularities are probably due to the measurement method and do not represent the actual behaviour of

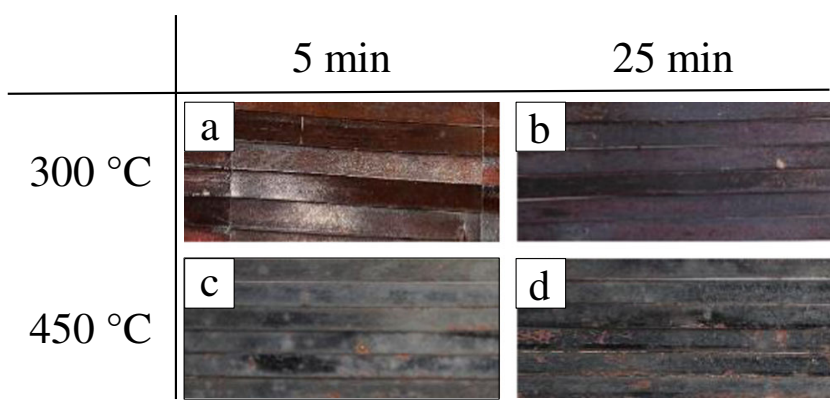

Fig. 8 The surface of the oxidised samples
Green Laser $(520 \mathrm{~nm})$

Blue Laser $(450 \mathrm{~nm}) \quad$ Fibre Laser $(1070 \mathrm{~nm})$

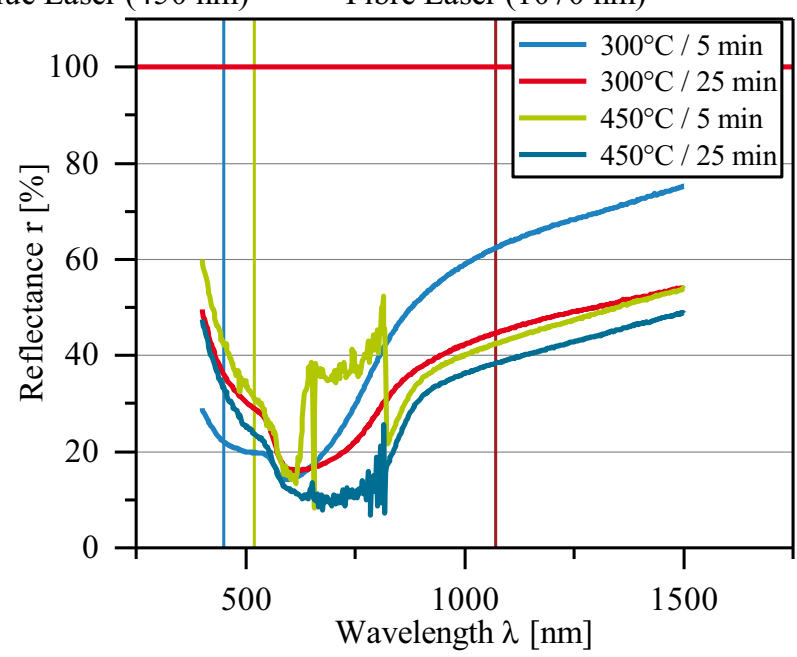

Fig. 9 Reflectance of the oxidised samples plotted over the wavelength. The reflectance of untreated copper ribbons is set to $100 \%$ and indicated by a horizontal line

the oxidised copper. It should be noted that when using visible wavelength sources (blue and green lasers), oxidation of the surface can achieve a greater increase in absorption compared to bare copper.

Using the laserbonder (Section 3.1), samples with untreated and oxidised ribbon are prepared as described in Section 3.2. The maximum tensile strength is measured as described in Section 3.3. At least five measured values are determined per parameter set. The result for the tensile strength is shown in Fig. 10. The tensile strength of the reference sample of untreated copper is marked as a horizontal line at about $155 \mathrm{~N} / \mathrm{mm}^{2}$. All average tensile strengths determined are below the value of the reference sample. The mean values of the samples oxidised at $450{ }^{\circ} \mathrm{C}$ are closer to the reference than the mean values of the samples oxidised at $300{ }^{\circ} \mathrm{C}$. This is mainly caused by an increase in the effective connection cross-section. However, due to the dispersion of the determined values, no reliable statement can be made.

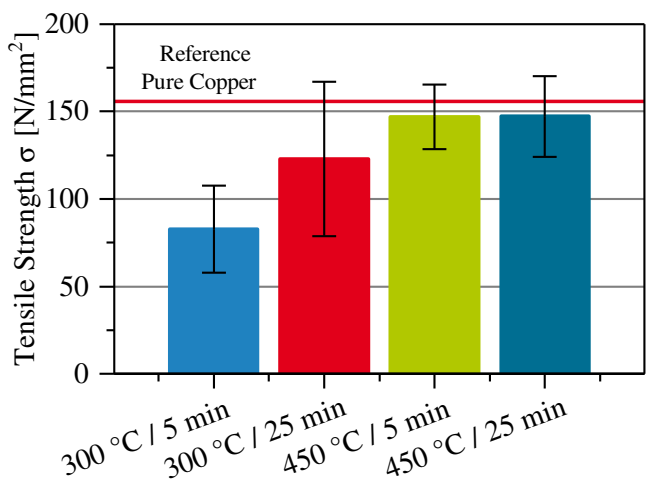

Fig. 10 Tensile strength of the oxidised samples. The horizontal red line marks the tensile strength of the reference sample (untreated copper) 
Oxidation of the samples increased absorption in the range of the used laser wavelength as well as the connection area for some samples with the same welding parameters. The reason for the lower tensile strength of the oxidised samples compared to the untreated reference is probably the presence of oxide particles in the joining zone. The copper ribbon is oxidised on both sides. On the upper side of the ribbon, the oxide layer ensures better absorption of the laser radiation and thus faster melting of the copper ribbon. On the underside of the ribbon, the oxide layer bursts open when melting through and the non-fusible particles remain in the molten pool. The brittleness of the oxide particles in comparison to the solidified melt may weaken the strength of the joint.

\subsection{Roughened samples}

To roughen the specimens, abrasives with different grain sizes are used according to ISO 6344. [11] has shown that working the surface with coarse-grained abrasive paper can lead to an increase in the degree of absorption. The selection of the grain size of the abrasive paper is made on the basis of the results presented by [11]. Sanding papers with grit sizes P400, P180, P100 and P60 are selected. Table 3 lists the grain diameters according to ISO 6344.

A ribbon grinder is constructed in which the ribbon is clamped and roughened on one side by the abrasive paper described. The aim is an evenly roughened surface in order to achieve absorption properties that are not location-dependent. Photos of the roughened samples are shown in Fig. 11.

Figure 12 shows the reflectance of the roughened samples over the wavelength. This is the relative reflectance compared to an untreated copper sample whose reflectance is set to $100 \%$.

Above the examined wavelength range of 400 to $1500 \mathrm{~nm}$, the relative reflectance of the measured samples is always above $80 \%$ compared to the untreated copper sample. Compared to the oxidised samples, the reflection behaviour has therefore changed less. In the wavelength range of the processing laser $(1070 \mathrm{~nm})$, the reflectance values of the samples are very close together (between 90 and 100\%). When examining the mechanical properties of the weld joint, similar results are expected as for the reference sample.

Using the laserbonder (Section 3.1), samples with untreated and roughened ribbons are prepared as described in Section 4.1.

Table 3 Comparison of grain size according to ISO 6344 [12]

\begin{tabular}{ll}
\hline Grit ISO 6344 & Grit size \\
\hline P60 & $297-250 \mu \mathrm{m}$ \\
P100 & $149-125 \mu \mathrm{m}$ \\
P180 & $88-74 \mu \mathrm{m}$ \\
P400 & $31-24 \mu \mathrm{m}$ \\
\hline
\end{tabular}

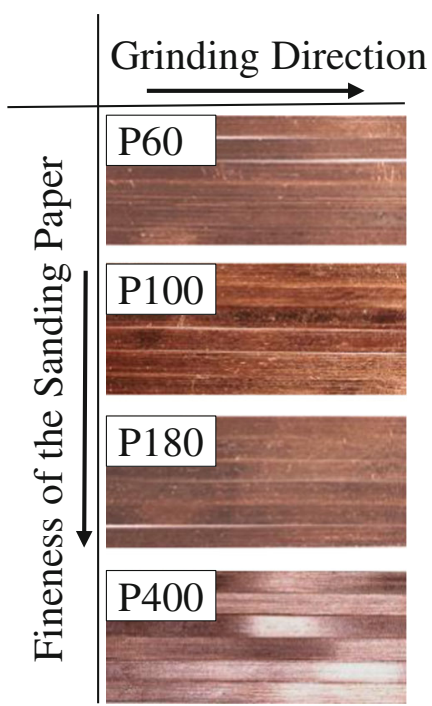

Fig. 11 The surface of the roughened samples

The maximum tensile strength is measured as described in Section 3.3. At least five measured values are determined per parameter set. The results of the tensile strength are shown in Fig. 13. The tensile strength of the reference sample of untreated copper is marked as a red line. All average tensile strengths determined are significantly below the value of the reference sample. Furthermore, there is no trend in the resulting mechanical strength in relation to the grain size.

Taking into account the measurement of the relative absorption behaviour, this result is initially surprising. A possible explanation for the discrepancy is the diameter of the focused laser beam $(\sim 25 \mu \mathrm{m}$, Table 1$)$. The grain sizes of the abrasive paper used are in the range of 24-297 $\mu \mathrm{m}$ (see Table 3). Therefore, the spot diameter is just as large as the smallest grain to be expected on the abrasive paper. The

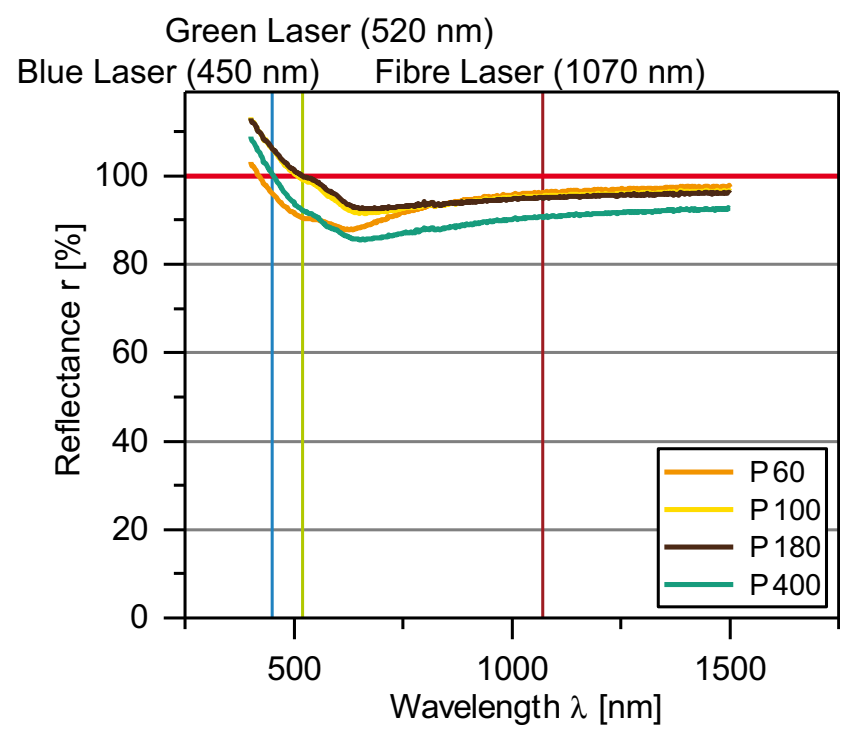

Fig. 12 Reflectance of the roughened samples plotted over the wavelength. The reflectance of the untreated copper ribbon is set to $100 \%$ and marked as a red line 


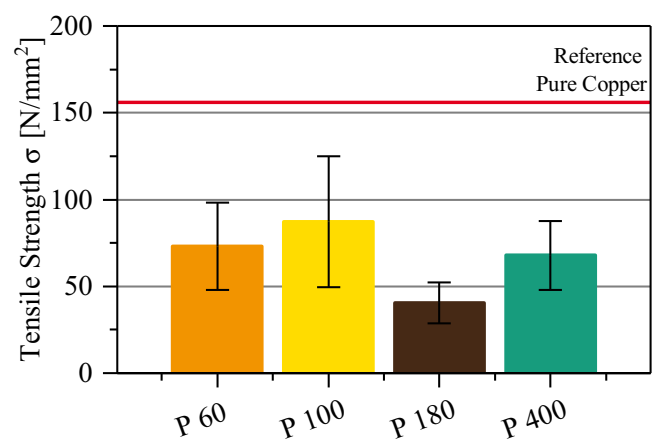

Fig. 13 Tensile strength of the roughened samples. The horizontal red line marks the tensile strength of the reference sample (untreated copper)

increase in the absorption coefficient of roughened surfaces is based on the theory of multiple reflections and the impingement of the beam at the Brewster angle [13]. The roughness generated by the abrasive paper used is probably too coarse to cause multiple reflections with this laser wavelength and spot diameter. The diameter of the measuring beam of the spectrometer is significantly larger than the spot diameter of the processing beam source, which explains the measured reflectance in Fig. 12.

\section{Summary}

The aim of this work is to investigate the influence of the surface properties of the copper connector on a laser microwelding process. For this purpose, commercially available copper ribbons are oxidised under controlled temperature and time conditions and roughened using abrasive paper. The reflective properties of these samples are examined and compared with an untreated copper sample. The modified copper ribbons are welded, using the laserbonder, to produce test samples. The mechanical strength of the resulting test welds is examined.

Despite a lower degree of reflection of the modified copper strips in comparison to an untreated copper sample, the mechanical strength of the resulting weld is reduced. For the oxidised samples, infusible, brittle oxide particles in the joining zone are identified as a possible cause. Abrasive paper with a macrograin was used to roughen the ribbons. According to the results of [13], it is assumed that the resulting roughness parameters of the copper surface are too coarse to lead to multiple reflections of the used laser beam. Surface roughening as well as oxidation of the copper ribbons may be easily integrated into the production process. Therefore, these techniques are qualified to modify the surface properties of the copper ribbon to increase the absorption rates and thus lead to a stable and reproducible laser beam welding process. But roughening the copper surface with brushes or abrasive paper does not result in a mechanically improved connection as this work has shown. To realize a beam trap, much smaller structures are necessary which cannot be gained with a relatively coarse material. This method does not lead to the desired effect. Oxidation shows greater absorption rates compared with an untreated copper surface, and the tensile strength of the resulting connection is acceptable. This method is suitable to improve laser welding of copper with IR beam sources, but further investigation is needed to qualify the relationship between the properties of the oxide layer and the resulting weld.

\section{Further investigation}

A reduction of the mechanical properties can be accepted for many applications in the field of joining technology, if a reproducible and reliable process control can be guaranteed. A reduction of the electrical properties would only be acceptable in a few cases. In a next step, the electrical properties of oxidised copper conductors are compared with those of an untreated copper sample.

Regarding roughening of the surface of the copper connector, finer abrasive papers (with grains in the area of the processing wavelength) are mechanically examined. According to [13], an improved coupling of the radiation is to be expected, which allows an earlier melting of the copper connector. This increases the connection area and thus the mechanical strength with the same required energy input.

Funding information This work was supported by the Federal Ministry for Economic Affairs and Energy in the frame of the FlexJoin project under the contract number $01 \mathrm{MX} 15010 \mathrm{~B}$.

Open Access This article is distributed under the terms of the Creative Commons Attribution 4.0 International License (http:// creativecommons.org/licenses/by/4.0/), which permits unrestricted use, distribution, and reproduction in any medium, provided you give appropriate credit to the original author(s) and the source, provide a link to the Creative Commons license, and indicate if changes were made.

\section{References}

1. Umweltbundesamt (2017) Indikator: Emission von Treibhausgasen. https://www.umweltbundesamt.de/indikatoremission-von-treibhausgasen\#textpart-1. Accessed 19 June 2018

2. Poprawe R (2005) Lasertechnik für die Fertigung: Grundlagen, Perspektiven und Beispiele für den innovativen Ingenieur. Springer, Berlin

3. Leitz A (2016) Laserstrahlschweißen von Kupfer- und Aluminiumwerkstoffen in Mischverbindungen. Herbert Utz Verlag Wissenschaft, Munich

4. Dilthey U (2006) Schweißtechnische Fertigungsverfahren 1: Schweiß- und Schneidtechnologien. Springer, Berlin

5. Schmitt F (2012) Laserstrahl-Mikroschweissen mit Strahlquellen hoher Brillanz und örtlicher Leistungsmodulation. Dissertation, RWTH Aachen University

6. Mehlmann B, Olowinsky A, Thuilot M, Gillner A (2014) Spatially modulated laser beam micro welding of $\mathrm{CuSn} 6$ and nickel-plated 
DC04 steel for battery applications. J Laser Micro/Nanoeng 9(3): 276-281. https://doi.org/10.2961/jlmn.2014.03.0019

7. Grupp M, Reinermann N (2017) Copper welding with highbrightness fiber lasers. Laser Technik J 14(3):25-29. https://doi. org/10.1002/latj.201700014

8. Lee S, Kim T, Hu S, Cai W, Abell J (2011) Joining technologies for automotive lithium-ion battery manufacturing: a review. ASME 2010 International Manufacturing Science and Engineering Conference, Pennsylvania, USA. ASME 1:541-549, New York

9. Mehlmann B, Gehlen E, Olowinsky A, Gillner A (2014) Laser micro welding for ribbon bonding. Phys Procedia 56:776-781. https://doi.org/10.1016/j.phpro.2014.08.085

10. Helm J, Schwetlick M, Olowinsky A, Gillner A, Poprawe R (2016) Connecting Battery Cells by Aluminium Ribbon Bonding using Laser Micro Welding. Proceedings of ICALEO 2016 -
International Congress on Applications of Lasers \& ElectroOptics, San Diego, USA

11. Xie J, Kar A (1999) Laser welding of thin sheet steel with surface oxidation. Weld J 78(10):343-348

12. Hofmann H, Spindler J (2015) Verfahren in der Beschichtungs- und Oberflächentechnik. Carl Hanser Verlag, Munich

13. Bergström D (2008) Absorption of laser light by rough metal surfaces. Dissertation, Luleå University of Technology, Sweden

Publisher's note Springer Nature remains neutral with regard to jurisdictional claims in published maps and institutional affiliations. 